\title{
Neurosharing: large-scale data sets (spike, LFP) recorded from the hippocampal-entorhinal system in behaving rats [version
}

\section{1; peer review: 4 approved]}

\section{Kenji Mizuseki1-3, Kamran Diba2,4, Eva Pastalkova2,5, Jeff Teeters ${ }^{6}$, Anton Sirota2,7, György Buzsáki1,2,8}

\author{
${ }^{1}$ NYU Neuroscience Institute, Langone Medical Center, New York University, New York, NY, USA \\ ${ }^{2}$ Center for Molecular and Behavioral Neuroscience, Rutgers, The State University of New Jersey, Newark, NJ, USA \\ ${ }^{3}$ Allen Institute for Brain Science, Seattle, WA, USA \\ ${ }^{4}$ Department of Psychology, University of Wisconsin at Milwaukee, Milwaukee, WI, USA \\ 5Janelia Farm Research Campus, Howard Hughes Medical Institute, Ashburn, VA, USA \\ ${ }^{6}$ Redwood Center for Theoretical Neuroscience, University of California, Berkeley, Berkeley, CA, USA \\ ${ }^{7}$ Centre for Integrative Neuroscience, University of Tübingen, Tübingen, Germany \\ ${ }^{8}$ Center for Neural Science, New York University, New York, NY, USA
}

V1 First published: 30 Apr 2014, 3:98

https://doi.org/10.12688/f1000research.3895.1

Latest published: $18 \mathrm{Jul} 2014, \mathbf{3 : 9 8}$

https://doi.org/10.12688/f1000research.3895.2

\section{Abstract}

Using silicon-based recording electrodes, we recorded neuronal activity of the dorsal hippocampus and dorsomedial entorhinal cortex from behaving rats. The entorhinal neurons were classified as principal neurons and interneurons based on monosynaptic interactions and wave-shapes. The hippocampal neurons were classified as principal neurons and interneurons based on monosynaptic interactions, wave-shapes and burstiness. The data set contains recordings from 7,736 neurons $(6,100$ classified as principal neurons, 1,132 as interneurons, and 504 cells that did not clearly fit into either category) obtained during 442 recording sessions from 11 rats (a total of 204.5 hours) while they were engaged in one of eight different behaviours/tasks. Both original and processed data (time stamp of spikes, spike waveforms, result of spike sorting and local field potential) are included, along with metadata of behavioural markers. Community-driven data sharing may offer cross-validation of findings, refinement of interpretations and facilitate discoveries.

\section{“incf}

This article is included in the INCF gateway.

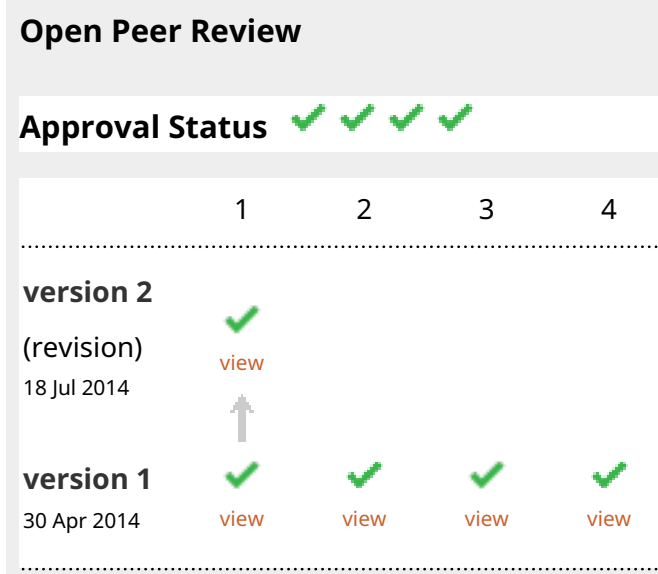

1. Yoshikazu Isomura, Tamagawa University,

Tokyo, Japan

2. Shuzo Sakata, University of Strathclyde,

Glasgow, UK

3. Andrew P. Maurer, University of Arizona,

Tucson, AZ, USA

4. James Knierim, Johns Hopkins University,

Baltimore, MD, USA

Any reports and responses or comments on the article can be found at the end of the article. 
This article is included in the Data: Use and

Reuse collection.

Corresponding authors: Kenji Mizuseki (kenjim@alleninstitute.org), György Buzsáki (Gyorgy.Buzsaki@nyumc.org)

Competing interests: No competing interests were disclosed.

Grant information: The research was supported by Uehara Memorial Foundation Research Fellowship (KM), Astellas Foundation for Research on Metabolic Disorders Research Fellowship (KM), Japan Society for the Promotion of Science's Postdoctoral Fellowship for Research Abroad (KM), NIH NS034994 (GB), NIH MH54671 (GB), NS074015 (GB), National Science Foundation Grant S E 0542013 (GB), The Human Frontier Science Program(GB), the James S. McDonnell Foundation (GB), the Kavli Foundation (GB), General Electric, Inc. (GB), HHMI (EP), Patterson Trust (EP), National Science Foundation Grant 0855272 (JT).

The funders had no role in study design, data collection and analysis, decision to publish, or preparation of the manuscript.

Copyright: $\odot 2014$ Mizuseki K et al. This is an open access article distributed under the terms of the Creative Commons Attribution License, which permits unrestricted use, distribution, and reproduction in any medium, provided the original work is properly cited.

How to cite this article: Mizuseki K, Diba K, Pastalkova E et al. Neurosharing: large-scale data sets (spike, LFP) recorded from the hippocampal-entorhinal system in behaving rats [version 1; peer review: 4 approved] F1000Research 2014, 3:98 https://doi.org/10.12688/f1000research.3895.1

First published: 30 Apr 2014, 3:98 https://doi.org/10.12688/f1000research.3895.1 


\section{Introduction}

The hippocampus and entorhinal cortex are essential structures for memory and spatial navigation ${ }^{1-8}$. Position-tuned cells ("place cells') are present in CA1, CA3 and dentate gyrus regions ${ }^{1,9}$. Grid cells, head direction cells, and border cells have been described in the dorsomedial entorhinal cortex, and are critical ingredients of navigation systems $s^{5,7,8,10-13}$. The temporal coordination across the entorhinal cortex and hippocampus is secured by various oscillations, especially theta, gamma and sharp wave ripples ${ }^{14-21}$.

We recorded activity of neurons in these brain regions while animals performed various tasks, such as linear track, open maze, T-maze with wheel running delay, plus maze and zigzag maze, as well as recordings during sleep in the home cage. Extensive technical descriptions of the data sets described in this document are available in several published papers ${ }^{6,21-27}$.

Several questions related to memory, navigation, spike time patterns, population coding, neuronal interactions, neuronal classification, replay, sleep homeostasis and oscillations have been studied based on this datase $t^{6,21-41}$. However, this dataset may provide valuable information if subjected to yet further analyses. Improved spike sorting, neuron classification and more sophisticated analyses may extend and refine the initial conclusions and offer insights that were previously missed. For these reasons we provide both unprocessed (wide band) and processed versions of our data. In our experience, all methods have limitations and must undergo continuous revision. We believe that community-driven data sharing, cross-validation of data, unified data formats and large collaborative efforts will facilitate discovery and benefit future progress in neuroscience.

\section{Material and methods}

\section{Animal surgery}

All protocols were approved by the Institutional Animal Care and Use Committee of Rutgers University (protocol No. 90-042), and all experiments were performed at Rutgers University. Before surgery, one to four rats were housed in a single home cage (made of plastic; size $\mathrm{L}=45 \mathrm{~cm}, \mathrm{~W}=23.5 \mathrm{~cm}, \mathrm{H}=20 \mathrm{~cm}$ ). Wood shavings were used as bedding and dry pellets were provided as food. The animals were housed in a temperature controlled $\left(68^{\circ} \mathrm{F}\right)$, but not a specific pathogen free, environment under 12:12-hours light:dark cycle where light cycle was from 7AM to 7PM. After surgery, the rats were housed individually, and highly absorbent paper (Techboard, Shepherd Speciality Papers) was used as bedding, and the animal's health was assessed daily by the experimenters.

Details of surgery and recovery procedures have been previously described in detail ${ }^{42,43}$. Eleven Long Evans rats (male, 3-8 months old, 250-400 g) were deeply anesthetized with isoflurane (1-1.5\%). In two rats (f01_m and g01_m), two silicon probes were implanted (one in each hemisphere) and targeted CA1 region. In three rats (gor01, pin01 and vvp01), two probes (32- and/or 64-site silicon probes) were implanted in the left dorsal hippocampus, targeted to CA1 and CA3 separately, and advanced over sessions and days through overlying neocortical and hippocampal tissue. The probe positions were: rat pin01: CA3: at a 35 degree angle to coronal plane, centered on $2.8 \mathrm{~mm}$ posterior and $2.6 \mathrm{~mm}$ lateral to bregma.
CA1: 26.5 degree angle to vertical, at a 35 degree angle to coronal, centered on $4.6 \mathrm{~mm}$ posterior and $2.4 \mathrm{~mm}$ lateral to bregma; rat vvp01: CA3: at a 26.5 degree angle to coronal plane, centered on $2.8 \mathrm{~mm}$ posterior and $2.6 \mathrm{~mm}$ lateral to bregma. CA1: 26.5 degree angle to vertical, parallel to sagittal plane, centered on 4.4 $\mathrm{mm}$ posterior and $2.3 \mathrm{~mm}$ lateral to bregma; rat gor01: CA3: at a 26.5 degree angle to coronal plane, centered on $3.1 \mathrm{~mm}$ posterior, and $3.0 \mathrm{~mm}$ lateral to bregma. CA1: 26.5 degree angle to vertical, at a 45 degree angle to coronal plane, centered on $4.9 \mathrm{~mm}$ posterior and $1.5 \mathrm{~mm}$ lateral to bregma. In four rats (ec013, ec014, ec016 and i01_m), 32- or 64-site silicon probe(s) were implanted in the right dorsal hippocampus and recorded from CA1, CA3 or dentate gyrus, and another 4-shank silicon probe was implanted in the right dorsocaudal medial entorhinal cortex. In one rat (ec012), one 4-shank silicon probe was implanted in the right dorsocaudal medial entorhinal cortex. In rat ec012, ec013, ec014, and ec016, the probe targeting the entorhinal cortex was positioned such that the different shanks recorded from different layers ${ }^{21}$ (4.5 mm lateral from the midline; $0.1 \mathrm{~mm}$ anterior to the edge of the transverse sinus at a 20-25 degree angle in the sagittal plane with the tip pointing toward the anterior direction). In rat i01_m, the EC probe had 4 shanks and was positioned such that all shanks recorded from the same layer. For the hippocampus probe in rats ec013, ec014 and ec016, the shanks were aligned parallel to the septo-temporal axis of the hippocampus (45 degrees parasagittal), positioned centrally at $3.5 \mathrm{~mm}$ posterior from bregma and $2.5 \mathrm{~mm}$ lateral from the midline.

For all silicon probes used, each shank had eight recording sites (160 $\mu \mathrm{m}^{2}$ each site, 1-3-M $\Omega$ impedance), and intershank distance was $200 \mu \mathrm{m}$. Recordings sites were staggered to provide a two-dimensional arrangement $(20 \mu \mathrm{m} \text { vertical separation })^{44,45}$. The individual silicon probes were attached to respective microdrives and moved independently and slowly to the target. Two stainless steel screws inserted above the cerebellum were used as indifferent (reference) and ground electrodes during recordings. At the end of the physiological recordings during the behavioural tasks, a small anodal DC current $(2-5 \mu \mathrm{A}, 10 \mathrm{~s})$ was applied to recording sites 1 or 2 days before rats were deeply anesthetized and euthanized by perfusion with $10 \%$ formalin solution. The positions of the electrodes were confirmed histologically and reported previously in detail ${ }^{21,24}$.

\section{Behavioural testing}

After the animals recovered from surgery (1 to 2 weeks), physiological signals were recorded during eight different types of behaviours mostly during light cycles (see Table 1).

(1) On an elevated linear track $(250 \mathrm{~cm} \times 7 \mathrm{~cm})$, the animals were required to run back and forth to obtain water reward at both ends ${ }^{21}$. In three animals (gor01, pin01, and vvp01), a similar elevated track was used $(170 \mathrm{~cm} \times 6.2 \mathrm{~cm}$, with $22 \mathrm{~cm} \times 22 \mathrm{~cm}$ end platforms) that was shortened to 79 or $125 \mathrm{~cm}$ in some trials ${ }^{23,24}$.

(2) In the open field task, the rats chased randomly dispersed drops of water or pieces of Froot Loops (25 mg; Kellogg's) on an elevated open platform ${ }^{21}(180 \mathrm{~cm} \times 180 \mathrm{~cm}, 120 \mathrm{~cm}$ $\times 120 \mathrm{~cm}$ or $100 \mathrm{~cm} \times 200 \mathrm{~cm})$. 
Table 1. Behaviour descriptions.

\begin{tabular}{|c|c|c|}
\hline Behaviour & $\begin{array}{l}\text { Behaviour subclass } \\
\text { (Behaviour } \\
\text { identifier) }\end{array}$ & Description \\
\hline elevated linear track & linear & Linear track, $250 \mathrm{~cm} \times 7 \mathrm{~cm}$. \\
\hline elevated linear track & linearOne & $\begin{array}{l}\text { Linear track ( } 170 \mathrm{~cm} \times 6.2 \mathrm{~cm} \text {, with } 22 \mathrm{~cm} \times 22 \mathrm{~cm} \text { end platforms) that } \\
\text { was shortened to } 79 \text { or } 125 \mathrm{~cm} \text { in some trials } \\
\text { sometimes also lengthened). The same linear track was used in linearOne } \\
\text { and linearTwo but at different locations in the same recording room. The } \\
\text { center of the track was at the same position for linearOne and linearTwo, but } \\
\text { the track was at fixed } 36.9 \text { degree angles from each other, corresponding to } \\
\text { the diagonals of the } 480 \times 640 \text { pixel camera. }\end{array}$ \\
\hline elevated linear track & linearTwo & $\begin{array}{l}\text { Exactly the same as linearOne but the linear track was at different locations } \\
\text { in the same recording room. See linearOne. }\end{array}$ \\
\hline open field & bigSquare & $180 \mathrm{~cm} \times 180 \mathrm{~cm}$ \\
\hline open field & bigSquarePlus & $\begin{array}{l}180 \mathrm{~cm} \times 180 \mathrm{~cm} \text { square open field, divided by plus shaped walls put in the } \\
\text { center of the field. }\end{array}$ \\
\hline open field & midSquare & $120 \mathrm{~cm} \times 120 \mathrm{~cm}$ \\
\hline open field & Open & $100 \mathrm{~cm} \times 200 \mathrm{~cm}$ \\
\hline $\begin{array}{l}\text { rewarded wheel- } \\
\text { running task }\end{array}$ & wheel & Operant wheel running task, See Mizuseki et al., $2009^{21}$. \\
\hline $\begin{array}{l}\text { alternation task in } \\
\text { T-maze }\end{array}$ & Mwheel & $\begin{array}{l}\text { Alternation task in T-maze }(100 \mathrm{~cm} \times 120 \mathrm{~cm}) \text { with wheel running delay. See } \\
\text { Pastalkova et al., } 2008^{6}\end{array}$ \\
\hline $\begin{array}{l}\text { alternation task in } \\
\text { T-maze }\end{array}$ & Tmaze & $\begin{array}{l}\text { Alternation task in T-maze, the same as Mwheel but without delay period. } \\
\text { There were } 2.78 \text { camera pixels/cm, which converts to } 22.24 \text { units/cm for the } \\
\text {.whl files ( } 8 x \text { compression of pixels). }\end{array}$ \\
\hline elevated plus maze & plus & Plus maze. $100 \mathrm{~cm} \times 100 \mathrm{~cm}$. \\
\hline zigzag maze & Zigzag & $100 \mathrm{~cm} \times 200 \mathrm{~cm}$ zigzag maze. See Royer et al., $2010^{46}$. \\
\hline $\begin{array}{l}\text { wheel-running in } \\
\text { home cage }\end{array}$ & wheel_home & $\begin{array}{l}\text { Wheel running in home cage with free access to a wheel with no } \\
\text { reinforcement. }\end{array}$ \\
\hline sleep & sleep & Sleeping in home cage. \\
\hline
\end{tabular}

(3) In the rewarded wheel-running task, a wheel (diameter $=29$ $\mathrm{cm})$ was attached to a rectangular-shape box $(39 \mathrm{~cm} \times 39 \mathrm{~cm}$ $\times 39 \mathrm{~cm}$ ). The rat was required to run in the wheel continuously for 10 seconds, after which time a piece of Froot Loop was dropped in the box as reinforcement ${ }^{21}$.

(4) In the alternation task in the T-maze $(100 \mathrm{~cm} \times 120 \mathrm{~cm})$ with wheel running delay, the animal was required to run on a wheel attached to the waiting area for $10 \mathrm{sec}$, after which time the animal had access to the central arm of the T-maze, at the end of which the animal chose to turn right or left. The animal was rewarded with water if the choice was opposite to the previous one ${ }^{6}$.

(5) In the elevated plus maze $(100 \mathrm{~cm} \times 100 \mathrm{~cm})$, the rats were motivated to run to the ends of four corridors, where water was given every $30 \mathrm{~s}$.

(6) In the zigzag maze $(100 \mathrm{~cm} \times 200 \mathrm{~cm})$ with 11 corridors, the animals learned to run back and forth between two water wells; $100 \mu \mathrm{l}$ of water was delivered at each well ${ }^{1,22,25,46}$.

(7) In the wheel-running in home cage, a wheel (diameter $=29$ $\mathrm{cm})$ was attached to a rectangular-shape box $(39 \mathrm{~cm} \times 39 \mathrm{~cm}$ $\times 39 \mathrm{~cm}$ ) which was used as a home cage during the experiment. Rats had free access to the wheel, and ran on the wheel with no reinforcement.
(8) In the sleeping session, the rat slept in the home cage.

For recording of behaviour (1) to (6), animals were water-scheduled for 23 hours prior to the experiment. Otherwise, both dry food and water were provided ad libitum. For tracking the position of the animals, two small light-emitting diodes, mounted above the headstage, were recorded by a digital video camera (SONY) at $30 \mathrm{~Hz}$ resolution.

\section{Data collection and cell-type classification}

Detailed information about the recording system and spike sorting has been previously described ${ }^{21,24,42}$. Briefly, signals were amplified $(1,000 \times)$, bandpass-filtered $(1 \mathrm{~Hz}-5 \mathrm{kHz})$ and acquired continuously at $20 \mathrm{kHz}$ (DataMax system; RC Electronics) or $32,552 \mathrm{~Hz}$ (NeuraLynx, MT) at 16-bit resolution. After recording, the signals were down-sampled to $1,250 \mathrm{~Hz}$ (DataMax system) or $1,252 \mathrm{~Hz}$ (NeuraLynx system) for the local field potential (LFP) analysis. In electrophysiological recordings, positive polarity is from zero toward positive values. To maximize the detection of very slowly discharging ('silent') neurons ${ }^{47}$, clustering was performed on concatenated files of several behavioural and sleep sessions recorded at the same electrode position on the same recording day ${ }^{22,25-27}$. We made extensive use of publicly available analytical and display programs, which were developed in our laboratory (KlustaKwik ${ }^{48}$ available at http://sourceforge.net/projects/klustakwik/, Neuroscope ${ }^{49}$ 
available at http://neuroscope.sourceforge.net/, Klusters ${ }^{49}$ available at http://klusters.sourceforge.net/, NDmanager ${ }^{49}$ available at http://ndmanager.sourceforge.net/). The latest available version at the time was used in each case. Spike sorting was performed automatically, using KlustaKwik ${ }^{48}$, followed by manual adjustment of the clusters, with the help of autocorrelogram, cross-correlogram and spike wave-shape similarity matrix (Klusters software package ${ }^{49}$ ). Because none of the existing spike sorting algorithms is completely automated, manual adjustment is necessary ${ }^{48}$. This inevitably leads to some operator-dependent variability ${ }^{48}$; therefore, provided clusters are not always identical to those used in our previous publications. Hippocampal principal cells and interneurons were separated based on their burstiness, waveforms and short-term monosynaptic interactions $\mathrm{s}^{6,17,21,24,42}$. Classification of principal neurons and interneurons of entorhinal cortical neurons was based on waveforms and short-term monosynaptic interactions, and described previously in detail $^{21}$. A total of 3,113 (CA1), 882 (CA3), 66 (DG), 491 (EC2), 568
(EC3) and 551 (EC5) principal neurons and 420 (CA1), 198 (CA3), 52 (DG), 85 (EC2), 215 (EC3) and 91 (EC5) interneurons were identified and included in this data set (see Table 2-Table 4).

The tip of the probe either moved spontaneously relative to the brain or was moved by the experimenter between recording days to record from potentially different sets of neurons. However, we cannot exclude the possibility that some neurons recorded on different days were identical, because spikes recorded on each day were clustered separately, though in some instances neurons were recorded over multiple days. When we moved the electrodes, we waited for at least an hour before recording in order to stabilize the position of electrodes.

Data description

The data are available ${ }^{50}$ at CRCNS.org (http://dx.doi.org/10.6080/ K09G5JRZ). Details of the data collection, processing and storage

Table 2. Number of cells recorded. Top row: animal identifier. Left column: brain region. Brain region EC4 indicates either entorhinal cortex layer 3 or 5 (could not be determined which); region EC? indicates in entorhinal cortex, but without layer assignment.

\begin{tabular}{|c|c|c|c|c|c|c|c|c|c|c|c|c|}
\hline $\begin{array}{l}\text { Brain } \\
\text { region }\end{array}$ & ec012 & ec013 & ec014 & ec016 & f01_m & g01_m & gor01 & i01_m & j01_m & pin01 & vvp01 & total \\
\hline EC2 & & 311 & 180 & 112 & & & & & & & & 603 \\
\hline EC3 & 201 & 362 & 177 & 116 & & & & & & & & 856 \\
\hline EC4 & & 276 & & 57 & & & & & & & & 333 \\
\hline EC5 & 110 & 416 & 68 & 154 & & & & & & & & 748 \\
\hline EC? & & & & & & & & 82 & & & & 82 \\
\hline Total EC & 311 & 1365 & 425 & 439 & & & & 82 & & & & 2622 \\
\hline CA1 & & 1185 & 1136 & 661 & 99 & 145 & 50 & 309 & & 23 & 116 & 3724 \\
\hline CA3 & & 223 & & 646 & & & 153 & & & 45 & 56 & 1123 \\
\hline$D G$ & & 41 & & 94 & & & & & & & & 135 \\
\hline Unknown & & 39 & & & & & & 3 & 90 & & & 132 \\
\hline Total & 311 & 2853 & 1561 & 1840 & 99 & 145 & 203 & 394 & 90 & 68 & 172 & 7736 \\
\hline
\end{tabular}

Table 3. Number of principal cells. Top row: animal identifier. Left column: brain region.

\begin{tabular}{|c|c|c|c|c|c|c|c|c|c|c|c|c|}
\hline $\begin{array}{l}\text { Brain } \\
\text { region }\end{array}$ & ec012 & ec013 & ec014 & ec016 & f01_m & g01_m & gor01 & i01_m & j01_m & pin01 & vvp01 & total \\
\hline EC2 & & 248 & 146 & 97 & & & & & & & & 491 \\
\hline EC3 & 140 & 239 & 101 & 88 & & & & & & & & 568 \\
\hline EC4 & & 214 & & 46 & & & & & & & & 260 \\
\hline EC5 & 89 & 300 & 34 & 128 & & & & & & & & 551 \\
\hline EC? & & & & & & & & 51 & & & & 51 \\
\hline Total EC & 229 & 1001 & 281 & 359 & & & & 51 & & & & 1921 \\
\hline CA1 & & 887 & 995 & 577 & 79 & 131 & 42 & 289 & & 19 & 94 & 3113 \\
\hline CA3 & & 217 & & 443 & & & 138 & & & 41 & 43 & 882 \\
\hline$D G$ & & 18 & & 48 & & & & & & & & 66 \\
\hline Unknown & & 37 & & & & & & 1 & 80 & & & 118 \\
\hline Total & 229 & 2160 & 1276 & 1427 & 79 & 131 & 180 & 341 & 80 & 60 & 137 & 6100 \\
\hline
\end{tabular}


Table 4. Number of interneurons. Top row: animal identifier. Left column: brain region.

\begin{tabular}{|c|c|c|c|c|c|c|c|c|c|c|c|c|}
\hline $\begin{array}{l}\text { Brain } \\
\text { region }\end{array}$ & ec012 & ec013 & ec014 & ec016 & f01_m & g01_m & gor01 & i01_m & j01_m & pin01 & vvp01 & total \\
\hline EC2 & & 45 & 27 & 13 & & & & & & & & 85 \\
\hline EC3 & 37 & 89 & 66 & 23 & & & & & & & & 215 \\
\hline EC4 & & 31 & & 8 & & & & & & & & 39 \\
\hline EC5 & 16 & 36 & 20 & 19 & & & & & & & & 91 \\
\hline EC? & & & & & & & & 24 & & & & 24 \\
\hline Total EC & 53 & 201 & 113 & 63 & & & & 24 & & & & 454 \\
\hline CA1 & & 205 & 90 & 46 & 19 & 13 & 8 & 14 & & 3 & 22 & 420 \\
\hline CA3 & & 4 & & 174 & & & 14 & & & 2 & 4 & 198 \\
\hline DG & & 16 & & 36 & & & & & & & & 52 \\
\hline Unknown & & 1 & & & & & & 1 & 6 & & & 8 \\
\hline Total & 53 & 427 & 203 & 319 & 19 & 13 & 22 & 39 & 6 & 5 & 26 & 1132 \\
\hline
\end{tabular}

Table 5. Number of recording sessions. Top row: animal identifier. Left column: behaviour subclass.

\begin{tabular}{|c|c|c|c|c|c|c|c|c|c|c|c|c|}
\hline $\begin{array}{l}\text { Behaviour } \\
\text { subclass }\end{array}$ & ec012 & ec013 & ec014 & ec016 & f01_m & g01_m & gor01 & i01_m & j01_m & pin01 & vvp01 & total \\
\hline bigSquare & 24 & 45 & 4 & 13 & & & & 1 & 4 & & & 91 \\
\hline bigSquarePlus & & 2 & & & & & & & & & & 2 \\
\hline linear & 18 & 90 & 2 & 9 & & & & & & & & 119 \\
\hline linearOne & & & & & & & 3 & & & & 5 & 8 \\
\hline linearTwo & & & & & & & 3 & & & & 5 & 8 \\
\hline midSquare & & 4 & 8 & 2 & & & & & & & & 14 \\
\hline Mwheel & 28 & 16 & 8 & 14 & 8 & 7 & & 8 & & & & 89 \\
\hline Open & & & & & & & & & & & 3 & 3 \\
\hline plus & & 11 & & & & & & & & & & 11 \\
\hline sleep & & & 19 & 10 & & & & & & & 1 & 30 \\
\hline Tmaze & & & & & & & 2 & & & 3 & 1 & 6 \\
\hline wheel & & 40 & 8 & 9 & & & 1 & & & & & 58 \\
\hline wheel_home & & & & 2 & & & & & & & & 2 \\
\hline ZigZag & & & 1 & & & & & & & & & 1 \\
\hline Total & 70 & 208 & 50 & 59 & 8 & 7 & 9 & 9 & 4 & 3 & 15 & 442 \\
\hline
\end{tabular}

of data into files are included with the data set, including scripts useful for processing the data ${ }^{50}$. Here, we briefly summarize the data description.

The number of cells recorded from each animal and brain region is shown in Table 2.

Most of the recorded cells were classified as principal neurons or interneurons. The number of cells classified as principal and interneuron are shown in Table 3 and Table 4.

The 8 types of behaviours (see Behavioural Testing section) were further subdivided into 14 behaviour subclasses based on minor differences (e.g. size of maze) and used as behaviour identifiers in the dataset (Table 1).
The data were obtained during 442 recording sessions. During each session the animal performed one of the 14 behaviour subclasses. The number of recording sessions and behaviour subclasses used with each animal is shown in Table 5. The description of each behaviour subclass is given in Table 1 .

Data file organization

The data files for each recording session are stored in separate compressed tar archive files (i.e. with extension "tar.gz"). These files are organized into top-level directories, each of which contains data for sessions recorded on the same day using the same animal and electrode placement combination. Data from all sessions recorded from the same animal on the same day were merged for spike sorting. All merged sessions are stored in the same top-level directory in the data set at CRCNS.org. Therefore, the cell identification 
numbers assigned by the spike sorting are common to all sessions within a top-level directory, and are not specific to individual sessions. Details of the file organization are provided in the document "CRCNS.org hc3 data description" which is included with the data set.

\section{Metadata organization}

The metadata describing the data is stored in four tables that are included with the data set. Table cell has information about each spike sorted cell. Table session has information about each experimental session. Table epos contains information about the position of the electrodes. And table file has information about the ".tar.gz" and other files that are in the data set.
These tables are provided in CSV (comma-separated values) format, Excel format, and as tables in an SQLite database. SQLite (http://www.sqlite.org/) is a free, open source, SQL data base engine available for all common operating systems. These tables are related to each other through a field (named "topdir"), which has the name of top-level directories described above and is common to all four tables. The fields in each of these tables are listed in Listing 1. As described in file "CRCNS.org hc3 data description" the SQLite command interface can be used with these tables to generate summary statistics from the metadata and to locate data files that satisfy particular search criteria (for example, find data for cells of a specific type from a particular brain region and experimental behaviour).

Listing 1: Create table statements for tables: cell, session, file and epos. Fields for each of these tables are documented in the comments.

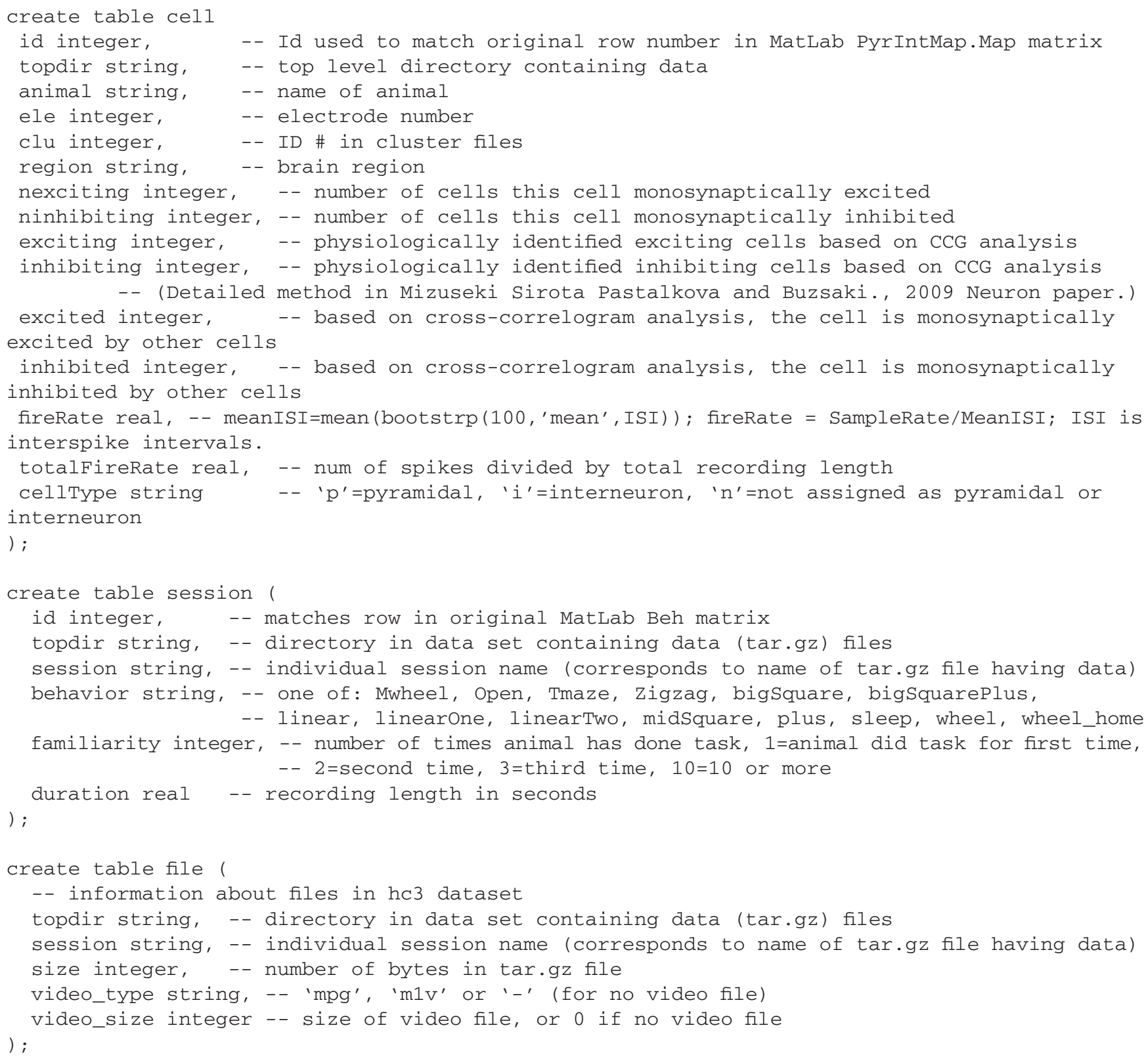




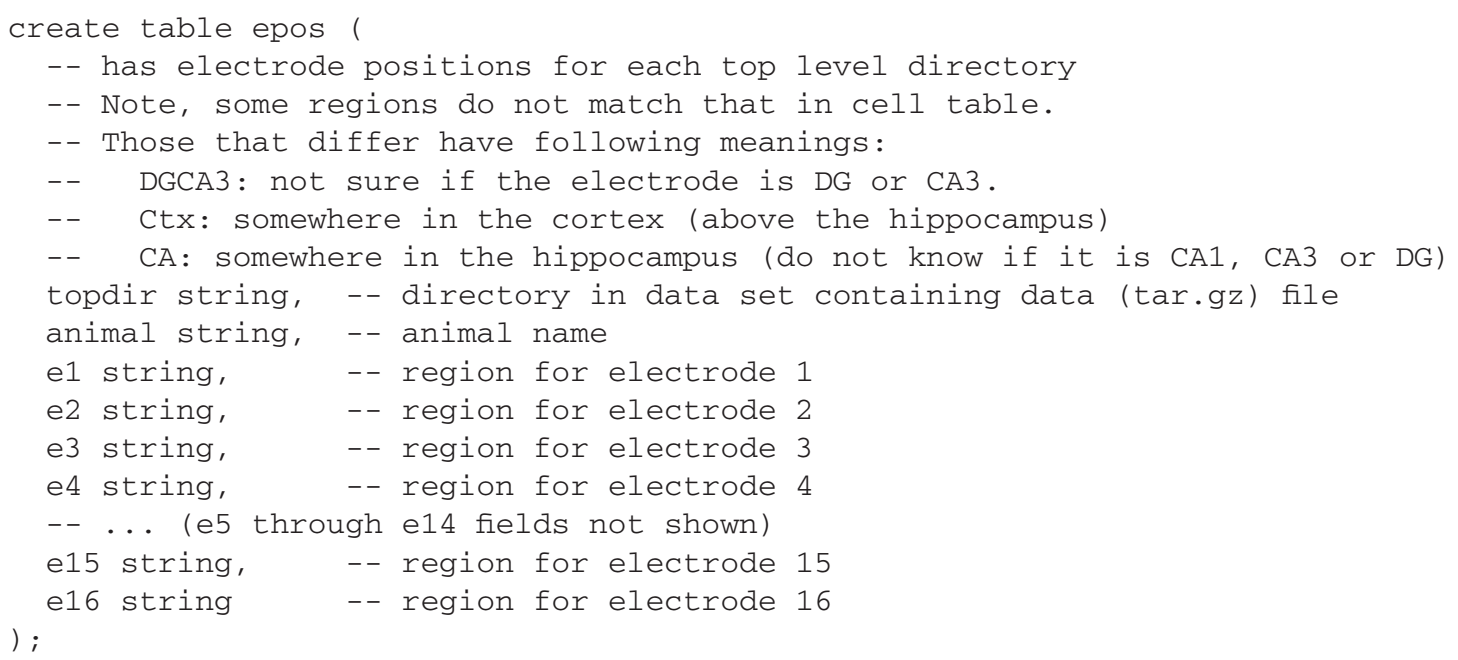

\section{Data availability}

CRCNS: Multiple single unit recordings from different rat hippocampal and entorhinal regions while the animals were performing multiple behavioral tasks, http://dx.doi.org/10.6080/K09G5JRZ

Terms of data usage: Data on this site is made available only for scientific purposes. Redistribution of the data is not permitted. Any publications derived from the data must cite the data contributors and CRCNS.org as being the source of the data and the original paper(s) that generated the data. Unnecessary downloading of large data files is not permitted. (To minimize demands on the server, only data expected to be useful for your scientific purposes should be downloaded).

Privacy notice: Occasionally the researchers who contribute data wish to know who has downloaded their data. Upon request we will provide this information to the data contributors. So, if you download data, there is a possibility that your name and email address will be provided to the data contributor. We request that the data contributors only use the information for legitimate scientific purposes (such as determining the frequency of downloads, or contacting users to providing updated information about the data or to explore possible collaborations).

\section{Author contributions}

$\mathrm{KM}, \mathrm{KD}, \mathrm{EP}$ and GB designed the experiments. KM, KD and EP carried out experiments and collected the data. KM collected data from rats ec012, ec013, ec014 and ec016. KD collected data from

rats gor01, pin01 and vvp01. EP collected data from rats f01_m, g01_m, i01_m and j01_m. KM carried out all spike sorting and classification of cell types in this dataset. JT prepared documentations for public data release (data sets hc-2 and hc-3) at CRCNS. org. AS prepared an earlier version of documentations for data set hc-2 at CRCNS.org. KM, JT and GB wrote the paper. All authors were involved in the revision of the draft manuscript and have agreed to the final content.

\section{Competing interests}

No competing interests were disclosed.

Grant information

The research was supported by Uehara Memorial Foundation Research Fellowship (KM), Astellas Foundation for Research on Metabolic Disorders Research Fellowship (KM), Japan Society for the Promotion of Science's Postdoctoral Fellowship for Research Abroad (KM), NIH NS034994 (GB), NIH MH54671 (GB), NIH NS074015 (GB), National Science Foundation Grant S E 0542013 (GB), The Human Frontier Science Program (GB), the James S. McDonnell Foundation (GB), the Kavli Foundation (GB), General Electric, Inc. (GB), HHMI (EP), Patterson Trust (EP), National Science Foundation Grant 0855272 (JT).

The funders had no role in study design, data collection and analysis, decision to publish, or preparation of the manuscript.

Acknowledgements

We thank Gautam Agarwal, Kenneth Harris and members of the Buzsaki lab for support and discussions.
1. O'Keefe J, Nadel L: The Hippocampus as a Cognitive Map (Oxford: Oxford University Press). 1978 Reference Source
2. Squire LR: Memory and the hippocampus: a synthesis from findings with rats, monkeys, and humans. Psychol Rev. 1992; 99(2): 195-231. PubMed Abstract | Publisher Full Text 
3. Eichenbaum H, Dudchenko P, Wood E, et al.: The hippocampus, memory, and place cells: is it spatial memory or a memory space? Neuron. 1999; 23(2): 209-226.

PubMed Abstract | Publisher Full Text

4. Buzsaki G: Theta rhythm of navigation: link between path integration and landmark navigation, episodic and semantic memory. Hippocampus. 2005 15(7): 827-840.

PubMed Abstract | Publisher Full Text

5. McNaughton BL, Battaglia FP, Jensen $\mathrm{O}$, et al.: Path integration and the neural basis of the 'cognitive map'. Nat Rev Neurosci. 2006; 7(8): 663-678. PubMed Abstract | Publisher Full Text

6. Pastalkova E, Itskov V, Amarasingham A, et al.: Internally generated cell assembly sequences in the rat hippocampus. Science. 2008; 321(5894): 1322-1327. PubMed Abstract | Publisher Full Text | Free Full Text

7. Buzsaki G, Moser El: Memory, navigation and theta rhythm in the hippocampalentorhinal system. Nat Neurosci. 2013; 16(2): 130-138.

PubMed Abstract | Publisher Full Text

8. Moser EI, Moser MB: Grid cells and neural coding in high-end cortices. Neuron 2013; 80(3): 765-774.

PubMed Abstract | Publisher Full Text

9. O'Keefe J, Dostrovsky J: The hippocampus as a spatial map. Preliminary evidence from unit activity in the freely-moving rat. Brain Res. 1971; 34(1) $171-175$

PubMed Abstract | Publisher Full Text

10. Hafting T, Fyhn M, Molden S, et al:: Microstructure of a spatial map in the entorhinal cortex. Nature. 2005; 436(7052): 801-806. PubMed Abstract | Publisher Full Text

11. Sargolini F, Fyhn M, Hafting T, et al:: Conjunctive representation of position, direction, and velocity in entorhinal cortex. Science. 2006; 312(5774): 758-762. PubMed Abstract | Publisher Full Text

12. Solstad T, Boccara CN, Kropff E, et al:: Representation of geometric borders in the entorhinal cortex. Science. 2008; 322(5909): 1865-1868. PubMed Abstract | Publisher Full Text

13. Savelli F, Yoganarasimha D, Knierim JJ: Influence of boundary removal on the spatial representations of the medial entorhinal cortex. Hippocampus. 2008; 18(12): 1270-1282.

PubMed Abstract | Publisher Full Text | Free Full Text

14. Buzsaki G, Horvath Z, Urioste R, et al:: High-frequency network oscillation in the hippocampus. Science. 1992; 256(5059): 1025-1027.

PubMed Abstract | Publisher Full Text

15. O'Keefe J, Recce ML: Phase relationship between hippocampal place units and the EEG theta rhythm. Hippocampus. 1993; 3(3): 317-330. PubMed Abstract | Publisher Full Text

16. Bragin A, Jando G, Nadasdy Z, et al:: Gamma (40-100 Hz) oscillation in the hippocampus of the behaving rat. $J$ Neurosci. 1995; 15(1 Pt 1): 47-60. PubMed Abstract

17. Skaggs WE, McNaughton BL, Wilson MA, et al: Theta phase precession in hippocampal neuronal populations and the compression of temporal sequences. Hippocampus. 1996; 6(2): 149-172. PubMed Abstract | Publisher Full Text

18. Buzsaki G: Theta oscillations in the hippocampus. Neuron. 2002; 33(3): 325-340. PubMed Abstract | Publisher Full Text

19. Buzsaki G: Rhythms of the Brain (New York: Oxford University Press). 2006. Reference Source

20. Buzsaki G, Wang XJ: Mechanisms of gamma oscillations. Annu Rev Neurosci. 2012; 35: 203-225. PubMed Abstract | Publisher Full Text

21. Mizuseki K, Sirota A, Pastalkova E, et al.: Theta oscillations provide temporal windows for local circuit computation in the entorhinal-hippocampal loop. Neuron. 2009; 64(2): 267-280

PubMed Abstract | Publisher Full Text | Free Full Text

22. Mizuseki K, Diba K, Pastalkova E, et al:: Hippocampal CA1 pyramidal cells form functionally distinct sublayers. Nat Neurosci. 2011; 14(9): 1174-1181. PubMed Abstract | Publisher Full Text | Free Full Text

23. Diba K, Buzsaki G: Forward and reverse hippocampal place-cell sequences during ripples. Nat Neurosci. 2007; 10(10): 1241-1242. PubMed Abstract | Publisher Full Text | Free Full Text

24. Diba K, Buzsaki G: Hippocampal network dynamics constrain the time lag between pyramidal cells across modified environments. J Neurosci. 2008; 28(50): 13448-13456

PubMed Abstract | Publisher Full Text | Free Full Text

25. Mizuseki K, Royer S, Diba K, et al:: Activity dynamics and behavioral correlates of CA3 and CA1 hippocampal pyramidal neurons. Hippocampus. 2012; 22(8): 1659-1680.

PubMed Abstract | Publisher Full Text | Free Full Text

26. Mizuseki K, Buzsaki G: Preconfigured, skewed distribution of firing rates in the hippocampus and entorhinal cortex. Cell Rep. 2013; 4(5): 1010-1021. PubMed Abstract | Publisher Full Text | Free Full Text

27. Mizuseki K, Buzsaki G: Theta oscillations decrease spike synchrony in the hippocampus and entorhinal cortex. Philos Trans R Soc Lond B Biol Sci. 2014; 369(1635): 20120530

PubMed Abstract | Publisher Full Text | Free Full Text
28. Belluscio MA, Mizuseki K, Schmidt R, et al.: Cross-frequency phase-phase coupling between theta and gamma oscillations in the hippocampus. J Neurosci. 2012; 32(2): 423-435.

PubMed Abstract | Publisher Full Text | Free Full Text

29. Geisler C, Diba K, Pastalkova E, et al:: Temporal delays among place cells determine the frequency of population theta oscillations in the hippocampus. Proc Natl Acad Sci U S A. 2010; 107(17): 7957-7962. PubMed Abstract | Publisher Full Text | Free Full Text

30. Grosmark AD, Mizuseki K, Pastalkova E, et al:: REM sleep reorganizes hippocampal excitability. Neuron. 2012; 75(6): 1001-1007. PubMed Abstract | Publisher Full Text | Free Full Text

31. Isomura $Y$, Sirota $A$, Ozen $S$, et al.: Integration and segregation of activity in entorhinal-hippocampal subregions by neocortical slow oscillations. Neuron 2006; 52(5): 871-882.

PubMed Abstract | Publisher Full Text

32. Itskov V, Pastalkova E, Mizuseki K, et al.: Theta-mediated dynamics of spatial information in hippocampus. J Neurosci. 2008; 28(23): 5959-5964. PubMed Abstract | Publisher Full Text | Free Full Text

33. Itskov V, Curto $\mathrm{C}$, Pastalkova $\mathrm{E}$, et al.: Cell assembly sequences arising from spike threshold adaptation keep track of time in the hippocampus. $J$ Neurosci. 2011; 31(8): 2828-2834. PubMed Abstract | Publisher Full Text | Free Full Text

34. Kempter R, Leibold C, Buzsaki G, et al:: Quantifying circular-linear associations: hippocampal phase precession. J Neurosci Methods. 2012; 207(1): 113-124. PubMed Abstract | Publisher Full Text

35. Schmidt R, Diba K, Leibold C, et al.: Single-trial phase precession in the hippocampus. J Neurosci. 2009; 29(42): 13232-13241.

PubMed Abstract | Publisher Full Text | Free Full Text

36. Sullivan D, Csicsvari J, Mizuseki K, et al.: Relationships between hippocampal sharp waves, ripples, and fast gamma oscillation: influence of dentate and entorhinal cortical activity. J Neurosci. 2011; 31(23): 8605-8616. PubMed Abstract | Publisher Full Text | Free Full Text

37. Sullivan D, Mizuseki K, Sorgi A, et al:: Comparison of sleep spindles and theta oscillations in the hippocampus. J Neurosci. 2014; 34(2): 662-674. PubMed Abstract | Publisher Full Text | Free Full Text

38. Schomburg EW, Anastassiou CA, Buzsaki G, et al:: The spiking component of oscillatory extracellular potentials in the rat hippocampus. J Neurosci. 2012; 32(34): 11798-11811.

PubMed Abstract | Publisher Full Text | Free Full Text

39. Taxidis J, Mizuseki K, Mason R, et al:: Influence of slow oscillation on hippocampa activity and ripples through cortico-hippocampal synaptic interactions, analyzed by a cortical-CA3-CA1 network model. Front Comput Neurosci. 2013; 7: 3. PubMed Abstract | Publisher Full Text | Free Full Text

40. Stevenson IH, London BM, Oby ER, et al:: Functional connectivity and tuning curves in populations of simultaneously recorded neurons. PLOS Comput Biol. 2012; 8(11): e1002775.

PubMed Abstract | Publisher Full Text | Free Full Text

41. Buzsaki G, Mizuseki K: The log-dynamic brain: how skewed distributions affect network operations. Nat Rev Neurosci. 2014; 15(4): 264-78. PubMed Abstract | Publisher Full Text

42. Csicsvari J, Hirase $\mathrm{H}, \mathrm{Czurko} \mathrm{A}$, et al:: Oscillatory coupling of hippocampal pyramidal cells and interneurons in the behaving Rat. J Neurosci. 1999; 19(1): 274-287. PubMed Abstract

43. Vandecasteele M, Royer MS, Belluscio S, et al:: Large-scale recording of neurons by movable silicon probes in behaving rodents. J Vis Exp. 2012; (61): e3568. PubMed Abstract | Publisher Full Text | Free Full Text

44. Csicsvari J, Henze DA, Jamieson B, et al:: Massively parallel recording of unit and local field potentials with silicon-based electrodes. J Neurophysiol. 2003; 90(2): 1314-1323

PubMed Abstract | Publisher Full Text

45. Fujisawa S, Amarasingham A, Harrison MT, et al.: Behavior-dependent short-term assembly dynamics in the medial prefrontal cortex. Nat Neurosci. 2008; 11(7): 823-833.

PubMed Abstract | Publisher Full Text | Free Full Text

46. Royer S, Sirota A, Patel J, et al.: Distinct representations and theta dynamics in dorsal and ventral hippocampus. J Neurosci. 2010; 30(5): 1777-1787. PubMed Abstract | Publisher Full Text | Free Full Text

47. Thompson LT, Best PJ: Place cells and silent cells in the hippocampus of freelybehaving rats. J Neurosci. 1989; 9(7): 2382-2390. PubMed Abstract

48. Harris KD, Henze DA, Csicsvari J, et al:: Accuracy of tetrode spike separation as determined by simultaneous intracellular and extracellular measurements. J Neurophysiol. 2000; 84(1): 401-414. PubMed Abstract

49. Hazan L, Zugaro M, Buzsaki G: Klusters, NeuroScope, NDManager: a free software suite for neurophysiological data processing and visualization J Neurosci Methods. 2006; 155(2): 207-216.

PubMed Abstract | Publisher Full Text

50. Mizuseki K, Sirota A, Pastalkova E, et al:: Multiple single unit recordings from different rat hippocampal and entorhinal regions while the animals were performing multiple behavioral tasks. CRCNS org. 2013. http://dx.doi. org/10.6080/K09G5JRZ.

Data Source 


\section{Open Peer Review}

\section{Current Peer Review Status:}

\section{Version 1}

Reviewer Report 07 May 2014

https://doi.org/10.5256/f1000research.4171.r4603

(C) 2014 Knierim J. This is an open access peer review report distributed under the terms of the Creative Commons Attribution License, which permits unrestricted use, distribution, and reproduction in any medium, provided the original work is properly cited.

\section{James Knierim}

Zanvyl Krieger Mind/Brain Institute and Department of Neuroscience, Johns Hopkins University, Baltimore, MD, USA

This data set will be a valuable resource for investigators who wish to test hypotheses about hippocampal function and interaction with entorhinal cortex at the level of single unit and LFP physiology. I have not investigated the data base carefully to ensure its utility, as I assume the authors have done so. My comments are limited to a few questions about their F1000Research article describing the data base.

1. 'Animal surgery' - second paragraph:

Do the authors mean "in the coronal plane?" It is not clear whether the tetrodes were angled medially or laterally in that plane, or whether the authors mean that the tetrodes were angled anteriorly or posteriorly to the coronal plane. Please clarify here and in other locations in the text how the tetrodes were angled.

2. 'Animal surgery' - final paragraph:

Does the data base contain histological figures? If not, are they easily identifiable and accessible from published reports? It would be very useful to ensure that the precise location of tetrodes could be made available to investigators.

3. Table 1, 'elevated linear track':

Shouldn't the fixed angles be 74 degrees (i.e. +/- 37 degrees)?

4. 'Behavioural testing' item (5):

Were the rats motivated to run the corridors in any particular order? Was there any working memory component to the trials? 
Competing Interests: No competing interests were disclosed.

I confirm that I have read this submission and believe that I have an appropriate level of expertise to confirm that it is of an acceptable scientific standard.

Reader Comment 14 Jul 2014

Kenji Mizuseki, Osaka City University Graduate School of Medicine, Japan

1. "Do the authors mean "in the coronal plane?" It is not clear whether the tetrodes were angled medially or laterally in that plane, or whether the authors mean that the tetrodes were angled anteriorly or posteriorly to the coronal plane. Please clarify here and in other locations in the text how the tetrodes were angled."

Indeed the description of probe implantation in the previous manuscript was not detailed enough. What we meant by 'to the coronal plane' was 'a plane formed by silicone probe shanks was 35 degrees to the coronal plane, roughly along the septotemoporal axis'. We provide accurate and complete descriptions of probe implantation in the revised manuscript.

2. "Does the data base contain histological figures? If not, are they easily identifiable and accessible from published reports? It would be very useful to ensure that the precise location of tetrodes could be made available to investigators."

The data set does not contain histological figures, but all available histological figures are reported in the previous publications. In the revised manuscript, we described the relationship between the animal identifiers in this paper and the animal identifiers in the previous publications so that one can easily identify the histology of the animal.

3. "Shouldn't the fixed angles be 74 degrees (i.e. +/- 37 degrees)?"

Yes, indeed this should be 74 degrees and we fixed it.

4. "Were the rats motivated to run the corridors in any particular order? Was there any working memory component to the trials?"

The plus maze had two open and two closed arms, and each arm had a water cup at the outer end of it. Before the session started, all the four water cups were filled with water $(\sim 20 \mu \mathrm{l})$. Once the animal consumed water in all of the water cups, water was given in two water cups in closed or open arms depending on which type of arms the animal visited and consumed the water lastly, that is, if the animal consumed the water in the closed arm lastly water was provided in water cups in the open arms (and vice versa). Afterword, when the animal consumed the water in the two water cups, water was given in the two water cups in the opposite type of arms to encourage the animal to visit all the wells with similar probability. We added this information in the revised manuscript. 
Competing Interests: No competing interests were disclosed.

Reviewer Report 06 May 2014

https://doi.org/10.5256/f1000research.4171.r4604

(c) 2014 Maurer A. This is an open access peer review report distributed under the terms of the Creative Commons Attribution License, which permits unrestricted use, distribution, and reproduction in any medium, provided the original work is properly cited.

\section{Andrew P. Maurer}

Division of Neural Systems Memory and Aging, University of Arizona, Tucson, AZ, USA

Mizuseki and colleagues provide a description of 442 datasets (more than 200 hours) of hippocampal in vivo recordings. These datasets provide cell classification as well as the raw data, in case users wish to return to the high-sample traces and re-cluster the data on their own. The results of different analyses from the database have been published, although all analysis possibilities have not been exhausted. While this is an atypical review to write (as any suggestions on improvement to the database seem to be akin to looking a gift horse in the mouth), I am hoping the authors can discuss the ramifications of providing such an extensive database. While any database has limitations (e.g. sometimes determining the EEG units is a bit of an exercise with these data in the present format), it is perhaps more advantageous and constructive to discuss what the community can do to make the most use of it. As the authors state "Community-driven data sharing may offer cross-validation of findings, refinement of interpretations and facilitate discoveries" and the challenges are now directed to those who are interested in participating in future analyses. In hopes that this will set-forth a new era of data-sharing, I hope that the authors can discuss their open database in a manner that parallels Giorgio Ascoli's discussion on sharing neural reconstruction files (Ascoli, 2006). It should be noted that I do not expect the authors to have comprehensive answers to each of my comments below, but it might be beneficial if they would provide some initial thoughts to seed further discussion. Some points that the authors may wish to discuss include:

1. One barrier to sharing data is "the fear of being scooped" (Ascoli, 2006). For example, scientific progress will be dramatically increased through parallel (and hopefully, collaborative) data analysis. Are the authors concerned about being "scooped"? What about a group of researchers unknowingly using the database to conduct an analysis that is also a student's PhD project? This hypothetical student may still be acquiring the expertise to keep pace with more seasoned researchers.

2. "An often unspoken resistance to the sharing... data is born out of concern for criticisms and mistakes" (Ascoli, 2006). This is an unprecedented event that Mizuseki and colleagues have set forth, by providing a comprehensive catalog of data in an unabashed manner. The first point I want to touch upon is the level of raw exposure in releasing data. I have never met a neuroscientist who believes that anyone else could've conducted their analyses better than themselves (save a modest few), but to find those who believe that the authors "didn't look 
for the right thing" could make up a small battalion. Mizuseki and colleagues invite critics to their doorstep. Perhaps this is more similar to posing nude as a model for artist. By placing data online, it comes with judgment and the potential to be proved wrong. What do the authors believe the convention is if others follow in their footsteps? For example, if group $A$ shares their database after publishing their results, group B downloads and analyzes their data in new light and finds the opposite results, what is the appropriate manner in handling the situation? The self-correction aspect of science is also accelerated when data is openlyshared. It remains to be seen how situations like this should/will be handled.

3. There is also a chance for the data to be used in order to stifle or impede publication when the result is dubious. That is, should it be considered "fair-play" for a reviewer to use the same database and conduct a similar analysis with results that contradict a submitted manuscript's results? A tactic such as this only seems appropriate in "open-review formats".

4. "A final barrier to sharing digital reconstructions relates to the reluctance to lose or give a competitive edge" (Ascoli, 2006). The release of this immense database will surely be the stronghold of many new assistant professors who are still in the initial stages of setting up a physiology laboratory. Moreover, I can see these data being used in laboratories that are heavily analysis driven and limited in their own capacity for high-density in vivo recordings. This increase in the number of people analyzing data invites competitors for the authors as well as their neutral peers. Sheer logic dictates that the authors are not afraid of competition (otherwise, why share the data? Please note that I am a cynic and have been taught by many reviewers that "scientific altruism" is as abundant as snarks and unicorns). Why should researchers not be afraid of others using this database to compete? Is it believed that these data will be used for collaboration? What can be done to emphasize collaboration across laboratories when using the database? How is authorship handled when multiple groups use these data? If I spend my time analyzing these data, only to have it published under a "group project name" (similar to Sir William Timothy Gowers' Polymath project), do I put it on my CV?

5. The paper explicitly states that large downloads are prohibited. Does this mean that I should not download all the data? Is it OK to use these data for a class project? If so, is it more appropriate for the professor to disseminate it to the students or should the students make their own CRCNS account? Finally, more of an afterthought but along similar lines: should there be a collaborative processing code library that should be developed and maintained in parallel with the use of these data (similar to GitHub or SourceForge)?

I absolutely do not expect the authors to have complete answers to these questions nor should they carry the sole responsibility of determining the general conventions of what constitutes use versus misuse, but I do think that it is worth hearing their general thoughts. As this is the largest and most comprehensive database of in vivo hippocampal and entorhinal physiology to become available to the general scientific community, there will be an immense ramification. Scientific replication/external validation is an immediate and positive application of this database. As I have cited Timothy Gowers above, I think it would be best to leave off with his opinion of open datasharing and collaboration: "It feels as though this process is to normal research as driving is to pushing a car." (http://gowers.wordpress.com/2009/02/01/questions-of-procedure/).

As a field we have the opportunity to compete or collaborate. I hope that these data facilitate 
cross-laboratory collaboration where two groups are reticent to share their own data. For those that are interested in embracing the collaborative spirit, the CRCNS website also has a "marketplace" section where ideas and potential collaborations can be discussed. Finally, I applaud the authors for this unprecedented act of scientific altruism. I hope this will be a platform that accelerates our understanding of the entorhinal-hippocampal circuitry through collaboration.

Competing Interests: No competing interests were disclosed.

\section{I confirm that I have read this submission and believe that I have an appropriate level of expertise to confirm that it is of an acceptable scientific standard.}

Reader Comment 15 Jul 2014

Kenji Mizuseki, Osaka City University Graduate School of Medicine, Japan

1. One barrier to sharing data is "the fear of being scooped" (Ascoli, 2006). For example, scientific progress will be dramatically increased through parallel (and hopefully, collaborative) data analysis. Are the authors concerned about being "scooped"? What about a group of researchers unknowingly using the database to conduct an analysis that is also a student's PhD project? This hypothetical student may still be acquiring the expertise to keep pace with more seasoned researchers.

We absolutely agree that "the fear of being scooped" is a big concern and for this reason some people feel strong resistance against data sharing. On the other hand, this fear is not specific to data sharing: similar experiments and analysis are underway by many groups independently every day with or without knowing that that is also a student or postdoc's project in other groups. Our tentative feeling is that, if the research group (principal investigator and his/her students and postdocs) is happy to share data publicly, we do not see any reason not to do so. If the group is not willing to share data due to the fear of being scooped, we do not see any reason to force them to share the data.

2. "An often unspoken resistance to the sharing... data is born out of concern for criticisms and mistakes" (Ascoli, 2006). This is an unprecedented event that Mizuseki and colleagues have set forth, by providing a comprehensive catalog of data in an unabashed manner. The first point I want to touch upon is the level of raw exposure in releasing data. I have never met a neuroscientist who believes that anyone else could've conducted their analyses better than themselves (save a modest few), but to find those who believe that the authors "didn't look for the right thing" could make up a small battalion. Mizuseki and colleagues invite critics to their doorstep. Perhaps this is more similar to posing nude as a model for artist. By placing data online, it comes with judgment and the potential to be proved wrong. What do the authors believe the convention is if others follow in their footsteps? For example, if group $A$ shares their database after publishing their results, group $B$ downloads and analyzes their data in new light and finds the opposite results, what is the appropriate manner in handling the situation? The self-correction aspect of science is also accelerated when data is openly-shared. It remains to be seen how situations like this should/will be handled. 
We fully agree that releasing data may be judged as "risky" by many. We have added this information to the text and cite Ascoli (2006). However, we think that this 'selfcorrection' process is a sound one and accelerates the progress in science in the long run. Since the scientific community has only a limited history of data sharing, good manner of data sharing should be formed in the community through experience.

3. There is also a chance for the data to be used in order to stifle or impede publication when the result is dubious. That is, should it be considered "fair-play" for a reviewer to use the same database and conduct a similar analysis with results that contradict a submitted manuscript's results? A tactic such as this only seems appropriate in "open-review formats".

Of course this should be judged case by case, but in general we think the situation the reviewer described is a fair-play and even a sound one. Tactics and politics should not be part of scientists' vocabulary. We need to assume that all of our colleagues are honest and they assume the same about us.

4. "A final barrier to sharing digital reconstructions relates to the reluctance to lose or give a competitive edge" (Ascoli, 2006). The release of this immense database will surely be the stronghold of many new assistant professors who are still in the initial stages of setting up a physiology laboratory. Moreover, I can see these data being used in laboratories that are heavily analysis driven and limited in their own capacity for high-density in vivo recordings. This increase in the number of people analyzing data invites competitors for the authors as well as their neutral peers. Sheer logic dictates that the authors are not afraid of competition (otherwise, why share the data? Please note that I am a cynic and have been taught by many reviewers that "scientific altruism" is as abundant as snarks and unicorns). Why should researchers not be afraid of others using this database to compete? Is it believed that these data will be used for collaboration? What can be done to emphasize collaboration across laboratories when using the database? How is authorship handled when multiple groups use these data? If I spend my time analyzing these data, only to have it published under a "group project name" (similar to Sir William Timothy Gowers' Polymath project), do I put it on my CV?

We do not have the answers to all these questions, of course. We can talk only about our opinions. Sharing data has two compelling reasons (1) The experiments were largely performed using public money, therefore it is only natural to return our results (data) to public at some point. (2) We cannot exhaust the every single possible analysis by ourselves, and other researchers may have much better idea and capability to analyze the data set to provide new insights.

5. The paper explicitly states that large downloads are prohibited. Does this mean that I should not download all the data? Is it OK to use these data for a class project? If so, is it more appropriate for the professor to disseminate it to the students or should the students make their own CRCNS account? Finally, more of an afterthought but along similar lines: should there be a collaborative processing code library that should be developed and maintained in parallel with the use of these data (similar to GitHub or SourceForge)? 
CRCNS terms allow downloading all the data. The guidelines (not preconditions) suggest that "Unnecessary downloading of large data files is not permitted." CRCNS just wants to avoid that industry and for-profit organizations will inappropriately use public data. If someone needs to download all the files for their scientific purpose, then it's OK. We modified the terms to allow sharing of downloaded data amongst direct colleagues working with the data or to students in a classroom. The CRCNS.org website does have forum that allows users to upload attachments that contain code or to reference code being developed at other sites, such as GitHub. Thanks for the suggestion to have a collaboratively developed code library that is more directly associated with data sets.

Competing Interests: No competing interests were disclosed.

Reviewer Report 06 May 2014

https://doi.org/10.5256/f1000research.4171.r4607

(c) 2014 Sakata S. This is an open access peer review report distributed under the terms of the Creative Commons Attribution License, which permits unrestricted use, distribution, and reproduction in any medium, provided the original work is properly cited.

\section{Shuzo Sakata}

Strathclyde Institute of Pharmacy and Biomedical Sciences, University of Strathclyde, Glasgow, UK

This is an important report for the neuroscience community regarding huge data sets recorded from the dorsal hippocampus and dorsomedial entorhinal cortex of behaving rats. Because the authors have already published a number of papers with the data sets, I have no doubt that this paper and their shared data will contribute to the further advancement of this field.

This manuscript is clearly written in details. This article can be improved by clarifying the following minor points in the section Data collection and cell-type classification:

\section{Cluster quality}

It is not clear whether the quality of single units was assessed objectively, for example, by measuring isolation distance.

\section{Cell-type classification}

Because now researchers including the authors can classify cell-types optogenetically, it would be better to comment on potential pitfalls of the classification procedure used here. For example, it is difficult to exclude the possibility that some of "principal" neurons can be interneurons.

Competing Interests: No competing interests were disclosed. 


\section{I confirm that I have read this submission and believe that I have an appropriate level of expertise to confirm that it is of an acceptable scientific standard.}

Reader Comment 15 Jul 2014

Kenji Mizuseki, Osaka City University Graduate School of Medicine, Japan

1. "It is not clear whether the quality of single units was assessed objectively, for example, by measuring isolation distance."

To check the quality of spike sorting, we calculated isolation distance ${ }^{1}$, an interspike interval index " $\mathrm{R}_{2 / 10}$ " ${ }^{2}$ and a fraction of interspike intervals less than $2 \mathrm{msec}^{3}$. In the revised manuscript, we explain that these values are available for each neuron so that one can choose well-isolated neurons by using these isolation quality measurements before downloading the data. We also mention that an initial quality control filtering was done in selecting cells to include in the data set: 7943 cells were detected, but only 7736 of them were included in the data set; 207 were not included because they were judged to have insufficient quality.

2. "Because now researchers including the authors can classify cell-types optogenetically, it would be better to comment on potential pitfalls of the classification procedure used here. For example, it is difficult to exclude the possibility that some of "principal" neurons can be interneurons."

This is an important point. Even though our classification of principal neurons and interneurons is supported by short-term spike cross-correlogram and consistent with previous reports ${ }^{4}{ }^{6}$ misclassification of pyramidal cells and interneurons is inevitable to some extent by our method. For example, some types of interneurons with wide wave shapes (e.g. somatostatin positive ineterneurons) might have been classified as pyramidal cells by our method ${ }^{7}$. The cell-type classification method should be verified and refined by optogenetical tools in the future. ${ }^{7891011} \mathrm{We}$ discuss this point in the revised manuscript.

\section{References}

1. Harris KD, Hirase $H$, Leinekugel $X$, Henze DA, et al.: Temporal interaction between single spikes and complex spike bursts in hippocampal pyramidal cells. Neuron.2001; 32 (1): 141149 PubMed Abstract | Publisher Full Text

2. Fee MS, Mitra PP, Kleinfeld D: Automatic sorting of multiple unit neuronal signals in the presence of anisotropic and non-Gaussian variability.J Neurosci Methods.1996; 69 (2): 175188 PubMed Abstract | Publisher Full Text

3. Takehara-Nishiuchi K, McNaughton BL: Spontaneous changes of neocortical code for associative memory during consolidation.Science.2008; 322 (5903): 960-963 PubMed Abstract | Publisher Full Text

4. Barthó P, Hiras H, Monconduit L, Zugaro M, et al.: Characterization of neocortical principal cells and interneurons by network interactions and extracellular features.J Neurophysiol.

2004; 92 (1): 600-608 PubMed Abstract | Publisher Full Text 
5. Quilichini P, Sirota A, Buzsáki G.: Intrinsic circuit organization and theta-gamma oscillation dynamics in the entorhinal cortex of the rat.J Neurosci.2010; 30 (33): 11128-11142 PubMed Abstract | Free Full Text | Publisher Full Text

6. Sirota A, Montgomery S, Fujisawa S, Isomura Y, et al.: Entrainment of neocortical neurons and gamma oscillations by the hippocampal theta rhythm.Neuron.2008; 60 (4): 683-697 PubMed Abstract | Free Full Text | Publisher Full Text

7. Royer S, Zemelman BV, Losonczy A, Kim J, et al.: Control of timing, rate and bursts of hippocampal place cells by dendritic and somatic inhibition.Nat Neurosci.2012; 15 (5): 769775 PubMed Abstract | Publisher Full Text

8. Madisen L, Mao T, Koch H, Zhuo JM, et al.: A toolbox of Cre-dependent optogenetic transgenic mice for light-induced activation and silencing.Nat Neurosci.2012; 15 (5): 793-802 PubMed Abstract | Free Full Text | Publisher Full Text

9. Stark E, Koos T, Buzsáki G.: Diode probes for spatiotemporal optical control of multiple neurons in freely moving animals.J Neurophysiol.2012; 108 (1): 349-363 PubMed Abstract | Free Full Text | Publisher Full Text

10. Stark E, Eichler R, Roux L, Fujisawa S, et al.: Inhibition-induced theta resonance in cortical circuits.Neuron.2013; 80 (5): 1263-1276 PubMed Abstract | Free Full Text | Publisher Full Text

11. Roux L, Stark E, Sjulson L, Buzsáki G.: In vivo optogenetic identification and manipulation of GABAergic interneuron subtypes.Curr Opin Neurobiol.2014; 26: 88-95 PubMed Abstract | Free Full Text | Publisher Full Text

Competing Interests: No competing interests were disclosed.

Reviewer Report 06 May 2014

https://doi.org/10.5256/f1000research.4171.r4602

(C) 2014 Isomura Y. This is an open access peer review report distributed under the terms of the Creative Commons Attribution License, which permits unrestricted use, distribution, and reproduction in any medium, provided the original work is properly cited.

\section{Yoshikazu Isomura}

Brain Science Institute, Tamagawa University, Tokyo, Japan

In this work, Mizuseki et al. provide valuable information on their large-scale data sets of multineuronal and local field potential (LFP) recordings from the hippocampus (dentate gyrus, CA3, and CA1) as well as the enthorhinal cortex across the layers (layers 2, 3, 4, 5 etc.) of behaving rats. These data sets have originally been used for a number of their excellent studies for past ten years. Here, they fully summarized the experimental conditions and results in individual recording sessions very clearly for any users to plan to analyze the data. It will be a really useful treasure map for all hippocampus researchers.

I have one minor comment. While they showed the number of isolated neurons in each brain area 
of each animal (Table 2 to Table 4), it is not clear yet how many neurons, at most, were recorded simultaneously. Some people will probably want to analyze spike activity in a population of many neurons. The data would be more available for the higher-order spike analysis if the authors added additional information on the best (or first choice) data set with a sufficient number of wellisolated neurons in the same brain area.

Competing Interests: No competing interests were disclosed.

\section{I confirm that I have read this submission and believe that I have an appropriate level of expertise to confirm that it is of an acceptable scientific standard.}

Reader Comment 15 Jul 2014

Kenji Mizuseki, Osaka City University Graduate School of Medicine, Japan

Indeed one should be able to know the number of neurons recorded in each recording sessions before downloading the data. Following the reviewer's advice, we added tables giving the number of spikes recorded from each neuron during each session to the metadata tables describing the data set and we provide examples in document "crcns-hc3data-description" of how to use these to find sessions useful for the researcher's purpose before downloading the data. In addition, we include a new set of documents (in file "crcnshc3-cell-counts.zip") that lists the sessions with the most cells from each region (for both all cells and well isolated units) and also lists - for all sessions - the number of cells recorded from each region (both all cells and well isolated). These documents can also be used to select sessions with the largest number of simultaneously recorded neurons from particular regions before downloading the data.

Competing Interests: No competing interests were disclosed.

The benefits of publishing with F1000Research:

- Your article is published within days, with no editorial bias

- You can publish traditional articles, null/negative results, case reports, data notes and more

- The peer review process is transparent and collaborative

- Your article is indexed in PubMed after passing peer review

- Dedicated customer support at every stage

For pre-submission enquiries, contact research@f1000.com 